\title{
A new data processing system for root growth and ramifi- cation analysis: description of methods
}

\author{
M. Colin-Belgrand ${ }^{1}$, H. Joannes², E. Dreyer ${ }^{3}$ and L. Pages ${ }^{4}$ \\ 1 Laboratoire des Sols et de la Nutrition des Arbres Forestiers, \\ 2 Station de Biométrie, and \\ 3 Laboratoire de Bioclimatologie et d'Ecophysiologie Forestière, INRA, Centre de Recherches \\ Forestières, BP 35, 54280 Seichamps, and \\ ${ }^{4}$ Station d'Agronomie, INRA, Centre d'Avignon, Domaine-de-Saint-Paul, 84000 Montfavet, France
}

\section{Introduction}

Direct observation of root growth in woody seedlings is possible using a 'minirhizotron'. Root growth in this device occurs almost exclusively at the interface between the substrate and the lower, transparent, rhizotron wall. This method provides a better picture of root morphology and development, but reduces a threedimensional root system to a plane. Root growth is generally observed every 2nd day; newly formed roots are traced on a transparent polyethylene sheet with a different color ink for each date.

Previous studies of root system characteristics required time consuming manual processing. To overcome this major limitation, we have recently developed a semiautomated data acquisition system allowing a quantitative analysis of root architecture (Belgrand et al., 1987). This new data processing system consists of 3 successive stages: 1) semi-automated data acquisition; 2) data storage and growth parameter computation; and 3) the integration of the computed parameters into a developmental model (Pages and Aries, 1988). The technical prerequisites of this processing system are described below.

\section{Data acquisition system}

Basic principles for analyzing structural features of root pictures are the following: 1) a root is defined as a linear, unbranched structure formed through the activity of a single apical meristem; 2) successive root orders are defined according to a developmental terminology (Rose, 1983): the taproot originating from the hypocotyl is the 1st order root and bears 2nd order roots and so on; 3) roots are treated as sets of elementary straight segments, each being the increment in root 


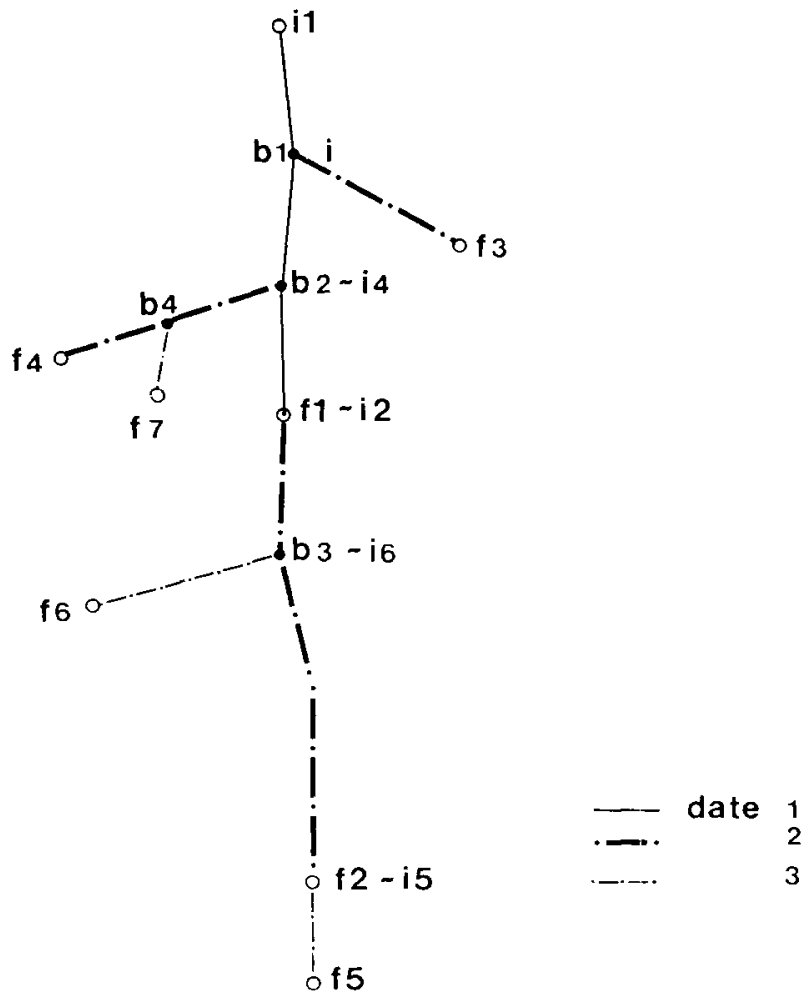

Fig. 1. Diagram of a simplified root system with 7 root segments, a taproot and 4 lateral second order roots. Successive dates are indicated by plain, broken and dotted lines. $i_{i}$ initial points; $f_{j}$; final points, and $b_{j}$ : branching points.

length between 2 successive observations; 4) each root segment is defined by the Cartesian coordinates of some characteristic points (e.g., terminal points (initial and final) and branching points where the laterals of the order $n+1$ appear); in fact, branching points are also the initial points of lateral root segments.

Fig. 1 shows a simplified root system with 7 segments belonging to 5 different roots, a taproot and 4 laterals. Root segment records are completed with automatically computed information about the segment position in the branching system hierarchy. Coordinates and 'structural' information are stored in the data storage structure.

Hardware needed for this processing is any IBM PC compatible computer equipped with a color video screen (EGA or VGA norm) and a graphics tablet. Software is written in TURBOPASCAL (version 4.0).

Digitizing begins at the root origin on the hypocotyl (the oldest observation). The observer provides some information about the experiment, the dates and associated color codes. He then introduces with the 
graphic mouse the initial point of the 1st segment, all the branching points along this segment in an acropetal order and the final point. This procedure is repeated for all segments on each date. All structural information about root order, segment identification, etc. are automatically computed without any direct intervention. Procedures for correction of errors and for help in the search for particular points (e.g., picture enlarging, cursor, etc.) are also provided.

\section{Data storage structure}

The data storage structure is made up of 3 data sets: a dictionary describing the experiment, the root segment records and the branching point records. This latter file contains some redundant information for redrawing root pictures more swiftly.

\section{Root segment file}

Each root segment contains some time information (time of emergence), spatial data (coordinates of its terminal and branching points) and a set of 'structural' indexes (Table 1): a sequential index specifying the order in which the segment was digitized (= root segment number); an origin index whose value is 1 if the segments is the 1st one on its root (new root) and 2 if it is the prolongation of a growing root; a date index; a color code associated with the date, for the video drawing; the coordinates of initial and final points $(X, Y)$; a link to the previous segment specifying the sequential index of the segment on which it is inserted; a running index which is the number of the root to which the segment belongs; the root order; the number of branching points; a following link index specifying the sequential index of the segment which follows on the same root and, finally, the rank of the branching point

Table I. Final data storage structure describing the simplified root system (Fig. 1).

\begin{tabular}{|c|c|c|c|c|c|c|c|c|c|c|c|}
\hline \multirow[t]{2}{*}{ Seq. } & \multirow{2}{*}{$\begin{array}{l}\text { Origin } \\
\text { index }\end{array}$} & \multirow{2}{*}{$\begin{array}{l}\text { Date } \\
\text { code }\end{array}$} & \multirow{2}{*}{ Color } & \multicolumn{2}{|c|}{ Coordinates } & \multirow{2}{*}{$\begin{array}{l}\text { Previous } \\
\text { index }\end{array}$} & \multirow{2}{*}{$\begin{array}{l}\text { Running } \\
\text { no. }\end{array}$} & \multirow{2}{*}{$\begin{array}{l}\text { Order } \\
\text { root }\end{array}$} & \multirow{2}{*}{$\begin{array}{l}\text { No. of } \\
\text { branch } \\
\text { pts }\end{array}$} & \multirow{2}{*}{$\begin{array}{l}\text { Following } \\
\text { index }\end{array}$} & \multirow{2}{*}{$\begin{array}{l}\text { Rank of } \\
\text { branching } \\
\text { pt }\end{array}$} \\
\hline & & & & $X_{i}, Y_{i}$ & $X_{f}, Y_{f}$ & & & & & & \\
\hline \multicolumn{12}{|c|}{ Taproot } \\
\hline 1 & 1 & 1 & red & i1 & $f 1$ & $\longrightarrow$ & 1 & 1 & 2 & 2 & 0 \\
\hline 2 & 2 & 2 & yell. & i2 & f2 & 1 & 1 & 1 & 1 & 5 & 0 \\
\hline 5 & 2 & 3 & blue & i5 & $f 5$ & 2 & 1 & 1 & 0 & 0 & 0 \\
\hline \multicolumn{12}{|c|}{ 2nd order roots } \\
\hline 3 & 1 & 2 & yell. & b1 & $\uparrow 3$ & 1 & 2 & 2 & 0 & 0 & 1 \\
\hline 4 & 1 & 3 & blue & b2 & $\mathrm{f4}$ & 1 & 3 & 2 & 1 & 0 & 2 \\
\hline 6 & 1 & 3 & blue & b3 & f6 & 2 & 4 & 2 & 0 & 0 & 0 \\
\hline \multicolumn{12}{|c|}{ 3rd order roots } \\
\hline 7 & 1 & 3 & blue & b4 & f7 & 1 & 5 & 3 & 0 & 0 & 0 \\
\hline
\end{tabular}

See text for significance of presented parameters. 
giving the position of the branch point on which the segment appeared. Its value is 0 if it is the prolongation of a growing root.

\section{Branching point file}

Each branch point record contains: 1) a sequential index of the root segment to which the branch point belongs (sequential index of the parent root); 2) a real lateral index: it is 1 if there is a previously digitized lateral segment and 0 if the branch point does not yet bear a lateral; 3) a virtual segment index: this parameter is used to help in the search for particular points during digitizing; in fact, branch points are not drawn on the video monitor, so, in order to facilitate branch point identification, virtual segments can be introduced. When the lateral root segment is finally introduced, 4) the virtual segment is automatically deleted; the coordinates of branch point and of final point of virtual segments; and 5) the rank of branch point.

Final data structure: resorting root segments

In order to facilitate the computation of root characteristics, a final data storage structure is created by reorganizing root segments through 3 successive sortings: 1) according to the running index, in other words, to the root to which they belong; 2) according to ascending root order; 3 ) according to the distance of branching point from origin of the parent root (Dbase). This final data organization allows a direct expression of the "hierarchic' position of each root in the ramified system and speeds up the computing of growth and ramification parameters. Table I shows the final data structure of the simplified example from Fig. 1.

\section{Growth and branching pattern analysis}

Statistical processing of computed coordinates allows the calculation of some root architectural characteristics. Each root is specified in terms of elongation and ramification. Some of them are time-independent, describing branching patterns (e.g., number of root, number of parent root, root order, branch angle, Dbase, interbranch distance and time of emergence); the others evolve with time (e.g., root elongation or velocity of lateral initiation, defined by length of the apical non-branching zone).

\section{Simulation of a growing root system}

This procedure uses a developmental and deterministic model in which the movement of each root tip is localized in time and space (three-dimensionally) (Pages and Aries, 1988). The parameters introduced in this model are specified for each root order. For oak seedling, taproot elongation is quasilinear (Elong $=a T+b$ ) and 2nd order root elongation is exponential (Elong $=a(1-\mathrm{e}-b T)$; the branching pattern is characterized by 5 parameters (basal non-branching zone length, interbranch distance, apical non-branching zone length, branch angle and numbers of generators) and geotropism coefficient (parameters not produced by the data acquisition system). Table II gives numerical parameters from a simulation of root architecture for a 2 mo old oak seedling.

\section{Discussion}

This new data acquisition system allows a quantitative analysis of root architecture 
Table II. Architectural parameters obtained for an oak (Quercus robur) seedling growing in a growth cabinet, used as the basis for a simulated program.

\begin{tabular}{|c|c|c|c|c|c|c|c|c|}
\hline \multirow[t]{2}{*}{$\begin{array}{l}\text { Root } \\
\text { order }\end{array}$} & \multirow[t]{2}{*}{$\begin{array}{l}\text { Branching } \\
\text { angle (rad.) }\end{array}$} & \multirow[t]{2}{*}{$\begin{array}{l}\text { No. of } \\
\text { gener. }\end{array}$} & \multirow[t]{2}{*}{$\begin{array}{l}\text { Geotropism } \\
\text { coefficient }\end{array}$} & \multicolumn{2}{|c|}{ Elongation law } & \multirow{2}{*}{$\begin{array}{l}\text { Basal } \\
\text { non-branch- } \\
\text { ing } \\
\text { length }(\mathrm{cm})\end{array}$} & \multirow{2}{*}{$\begin{array}{l}\text { Interbranch } \\
\text { distance }(\mathrm{cm})\end{array}$} & \multirow{2}{*}{$\begin{array}{l}\text { Apical non- } \\
\text { branching } \\
\text { length } \\
(\mathrm{cm})\end{array}$} \\
\hline & & & & $\begin{array}{l}\mathrm{a} \\
(\mathrm{cm} / \mathrm{d}\end{array}$ & & & & \\
\hline $\begin{array}{l}1 \\
2\end{array}$ & $\begin{array}{l}0.00 \\
1.36\end{array}$ & $\begin{array}{l}7 \\
2\end{array}$ & $\begin{array}{l}0.00 \\
0.20\end{array}$ & $\begin{array}{r}-3.20 \\
2.00\end{array}$ & $\begin{array}{l}1.67 \\
0.28\end{array}$ & $\begin{array}{l}0.25 \\
0.55\end{array}$ & 0.65 & 7.18 \\
\hline
\end{tabular}

with all dynamic aspects because the location of all branches and root tips are recorded in space and in each time step. This method will be very useful for studying the changes of root development induced by any stress of the substrate (e.g., waterlogging, water stress, chemical stress, influence of fertilizers). It could be applied to any ramified structure and allows a detailed analysis of growth and branching patterns.

\section{References}

Belgrand M., Dreyer E., Joannes H., Velter C. \& Scuiller 1. (1987) A semi-automated data processing system for root growth analysis: application to a growing oak seedling. Tree Physiol. 3, 393-404

Pages L. \& Aries F. (1988) Modèle architectural de base pour l'étude de la croissance et du développement du système racinaire. I. Le modèle. Agronomie 8, 888-897

Rose D.A. (1983) The description of the growth of root systems. Plant Soil 75, 405-415 